\title{
A STUDY OF CAPILLARY PERMEABILITY IN EXPERIMENTAL BURNS AND BURN SHOCK USING RADIOACTIVE DYES IN BLOOD AND LYMPH ${ }^{1}$
}

\author{
BY OLIVER COPE AND FRANCIS D. MOORE? \\ (From the Surgical Research and John Collins Warren Laboratories of Harvard University at the \\ Massachusetts General Hospital, Boston)
}

(Received for publication August 2, 1943)

The integrity of the capillary membrane is essential to the maintenance of the circulation in a normal animal. Increased loss of plasma colloids through the capillary wall may be an important factor in the development of a pathologic state. In recent years, interest has centered upon abnormal capillary permeability, and local changes in permeability have been demonstrated in areas of trauma and burn. A generalized increase in capillary permeability has been postulated in shock, but the evidence is conflicting. Known to occur when histamine is injected intravenously (1), it might take place in other types of shock and has been suggested as a reason for the irreversibility of late shock. The tissue anoxia that occurs as a result of prolonged low blood pressure and decreased blood flow in shock could result in an increase in capillary permeability which would not be limited to the site of injury.

Direct quantitative measurement of capillary permeability presents technical difficulties because of the microscopic character of the spaces involved. Several workers, including Krogh (2) and Landis (3), have succeeded in experimental animals in observing directly through a dissecting microscope the passage of dyes, particulate matter, and blood cells out of the capillary into the extravascular space. Landis (3), using a micro-pipette, has been able to measure capillary pressure in both animals and man. Such observations, while demonstrating that under experimental conditions the capillary wall is permeable to large molecules and even particulate matter, have not shown to what extent, in the intact animal with capillaries undisturbed by

\footnotetext{
1 The work described in this paper was done under a contract, recommended by the Committee on Medical Research, between the Office of Scientific Research and Development and Harvard University.

2 Fellow in the Medical Sciences, National Research Council.
}

manipulation, the capillary is permeable to colloids and at what rate this exchange of colloids across the capillary wall takes place.

Much of our knowledge of capillary permeability is the result of the use of indirect methods. The local concentration of colloidal dyes (4) or radioactive proteins (5) in tissues after injection of these substances into the blood stream has furnished information. Permeability has also been estimated by the flow and protein concentration of lymph. In 1932, Field, Drinker, and White (6) found that the flow of lymph from dogs' feet was augmented after immersion in hot water, revealing an increased filtration of plasma fluid and protein from the capillary into the interstitial space and thence into the lymphatic vessel. This local change in permeability in burns has been amply confirmed recently by Glenn, Petersen, and Drinker (7), and Glenn, Muus, and Drinker (8).

Neither of the two types of indirect method quoted has proven altogether satisfactory in the determination of capillary permeability. The use of the concentration of colloids in excised tissue may be misleading because of the difficulty of removing the blood from the tissue without also removing the extravascular, interstitial fluid. The method of Drinker, employing lymph flow, protein concentration, and their product as a measure of permeability, is open to doubt under conditions of reduced blood flow. The concentration of protein in the interstitial fluid (and therefore in the lymph) theoretically can be increased by absorption of fluid at the venous end of the capillary without any change in capillary permeability. And a decreased amount of protein may be found in the lymphatic trunk in the presence of increased capillary permeability if the blood flow is sufficiently reduced. Blood flow, except in an area of trauma, is commonly reduced in shock. 
Recently, Tobin and Moore (9) have synthesized radioactive colloidal dyes which by means of their radioactivity permit a more sensitive measurement of dye concentration. ${ }^{3}$ It was decided to adapt this dye technic to the study of capillary permeability by the simultaneous measurement of the radioactive concentrations in blood stream and lymph. Certain di-azo acid dyes form a chemical union with protein (11) and, when injected into the blood stream, rapidly combine with the plasma protein (12). Radioactive derivatives of these dyes also form this protein bond (9), and, in the blood stream, represent tagged molecules; the rate of their appearance in the lymph should prove an effective measure of capillary permeability.

Since the sole source of radioactivity in such an experiment is the blood stream into which the radioactive dye has been injected, the rate of appearance of radioactivity in the lymph must be a function of capillary filtration and cannot be the result of the accumulation of stagnant protein in the interstitial space.

In this paper are reported both the details of the method and the results obtained in experimental burns.

\section{METHODS}

A "tagged" colloidal dye, which becomes associated with protein in the serum, is used. This substance is injected into the blood stream and its slow permeation across the capillary into lymph measured, in samples of lymph, by a physical detection apparatus. Simultaneously, its disappearance from the serum is measured. Thus, a set of curves is obtained, one for serum decreasing with time, and several for lymph, from various sources, increasing with time. The relationship of these curves to each other is a direct quantitative measurement of the permeability of the capillaries from which the lymph flows.

The radioactive colloidal dyes used have been brominated derivatives of trypan blue and Evans blue (T-1824). Most of the experiments were done with the latter. The radioactive di-brom dyes have previously been described and their synthesis and properties, as well as measurement technics, have been discussed $(9,10,13)$. The radioactivity is due to the presence in the molecule of 2 atoms of radiobromine $\left(\mathrm{Br}^{82}\right)$, and the measurements which constitute the endpoints are carried out on a Geiger counter.

The bromo-dyes are colloidal in aqueous solution, as are their non-brominated counterparts. In protein-containing

\footnotetext{
${ }^{3}$ Such dyes have been shown by means of their radioactivity to collect in increasing concentration in areas of inflammation (10).
}

fluids, the dyes become associated with protein and if the protein is plasma protein, the dyes show a preferential affinity for albumin (12).4 This "dye-protein bond" is not well understood but appears to be chemical rather than adsorptive in nature; it is quantitative in proportion (11, 12).

The amount of dye injected in these experiments varied from 15 to $30 \mathrm{mgm}$. per $\mathrm{kgm}$. This dose is considerably higher than that ordinarily used for blood volume determinations with Evans blue because only extremely small amounts of dye normally appear in lymph early in the experiment, and it is necessary to give enough dye so that the early radioactive readings will be within the range of the Geiger counter. The serum concentration of dye at the start of the experiment is, therefore, in the range of 0.03 per cent to 0.05 per cent, and by the end of 3 hours has fallen to half this figure. This concentration is within the limits described by Rawson in which the dye is virtually entirely associated with albumin. The lymph concentration is, of course, much lower than this, and in the normal animal, the lymph from the leg or cervical lymphatic shows no gross color. The radioactive emanations, however, permit the detection of as little as $\mathbf{0 . 0 0 0 2 5}$ mgm. of the dye.

The radioactive figures used in the experiments are expressed in arbitrary "units" which are derived as follows. The Geiger counter readings (in "counts per minute") are made on samples of 0.5 to $1.0 \mathrm{cc}$. of lymph or serum. These determinations are corrected for decay according to the 34-hour half-life of the isotope involved. This result is then expressed in thousandths of a micro-curie (so-called "milli-micro-curie," determined by reference to a uranium standard as described by Moore and Tobin (10)). The plasma concentration at 3 hours is then taken as a reference point and defined as 10 units per cc. Whatever correction factor is required to bring the 3-hour reading to a numerical value of 10.0 is then applied to the entire experiment. ${ }^{b}$ Thus, a set of curves is obtained whose absolute level has been changed but whose relationship to each other is unaltered. Furthermore, the curves are readily comparable with other experiments in spite of the fact that the actual radioactive readings may have varied over a wide absolute range, due to the variation in strength of the original samples of radiobromine as they came from the cyclotron.

The protein determinations were made with the refractometer with frequent checks by Kjeldahl determinations. "Specific activity" of the protein, a ratio of the "active" to "inactive" protein present, is based on these protein readings and derived in a manner described in the following section.

${ }^{4}$ The authors are indebted to Dr. Rawson for demonstrating that these brominated dyes behave much as their non-brominated precursors.

${ }^{5}$ For example, if, at 3 hours, the serum concentration is $5.0 \mathrm{~m} . \mu \mathrm{c}$. per cc., a factor of $\times 2.0$ must be applied to make this value reach the arbitrary level of 10.0 "units" per cc. This factor of $\times 2.0$ is then applied to all the figures in the experiment. 
The animals used were dogs weighing from 15 to $25 \mathrm{kgm}$.; they were maintained under nembutal anesthesia, with the exception of a few in which control dye studies were made. Various lymphatic trunks were cannulated. The trunk of one or more legs was cannulated above the ankle joint, as described by Drinker (6). The cervical trunk on the left side, and the thoracic duct, were cannulated at a point near their entry into the left innominate vein. In addition to radioactivity, the rate of flow and the concentration of various chemical constituents of the lymph were measured before and after the burning of one or both hind feet to just above the ankle. Samples of arterial blood were removed at intervals from either the carotid or femoral arteries. The mean arterial blood pressure was recorded periodically with a mercury manometer by puncture with needle without interruption of the blood flow. The flow of lymph in the lymphatic trunks of the leg and neck is sluggish in the normal resting dog under nembutal anesthesia. In order to obtain sufficient lymph for analysis, it is usually necessary to stimulate the flow of the lymph from the foot by gentle massage of the foot pad. This massage is made to simulate the pressure on the pad of walking. The flow of lymph in the cervical trunk is stimulated by manually flexing the head on the neck (14), approximately 15 times per minute. Following burning of the leg, no massage or pressure was exerted.

The flow of lymph in the thoracic duct is so vigorous under normal conditions that the cannula has to be stoppered when samples are not being removed. The flow in the thoracic duct is generally maintained, even when the animal has a low blood pressure late in the shock state, but occasionally spontaneous flow disappears. It can then be produced readily by pressure on the abdomen. The method employed in cannulating the thoracic duct cuts off the normal flow from the duct into the vein. It is probable, though it was not demonstrated in these experiments, that the flow of lymph normally carried through the thoracic duct is continued to some extent through collaterals with the right thoracic lymphatic.

\section{EXPERIMENTS}

\section{Rate of formation of lymph}

Little is known regarding the rate of passage of water and electrolytes from blood stream to

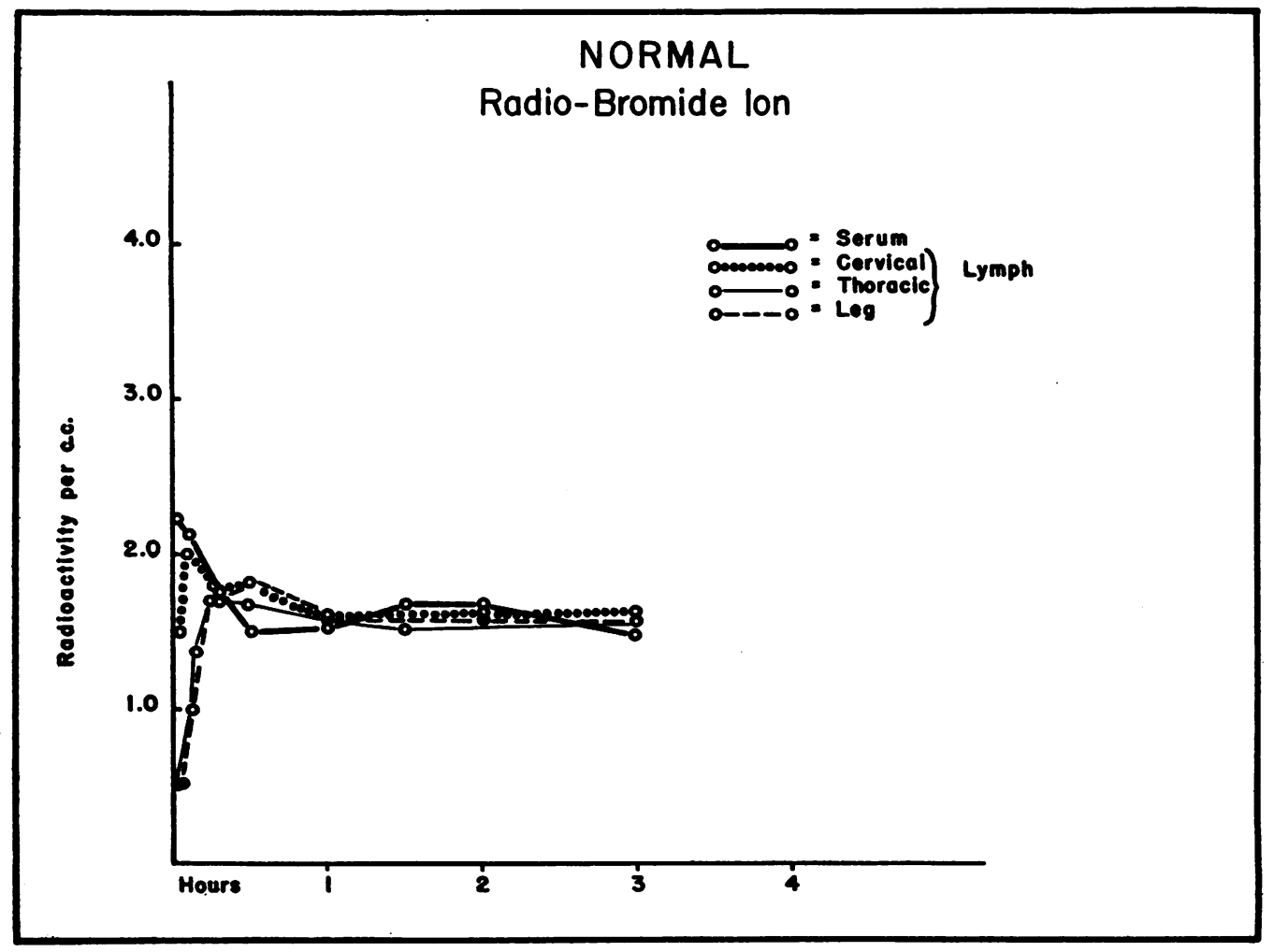

Fig. 1. Rate of Distribution in Blood and Lymph of Radioactive Bromide Ion in a Control DOG UNDER NEMBUTAL

The radioactive bromide $\left(\mathrm{Br}^{82}\right)$, as the sodium salt, was injected intravenously at 0 hours. Samples of blood serum, cervical, thoracic, and leg lymph were collected at 5-minute intervals during the first 20 minutes and at each half hour through the first 2 hours. Equal concentrations of radioactivity were reached in the various fluids at 20 minutes. 


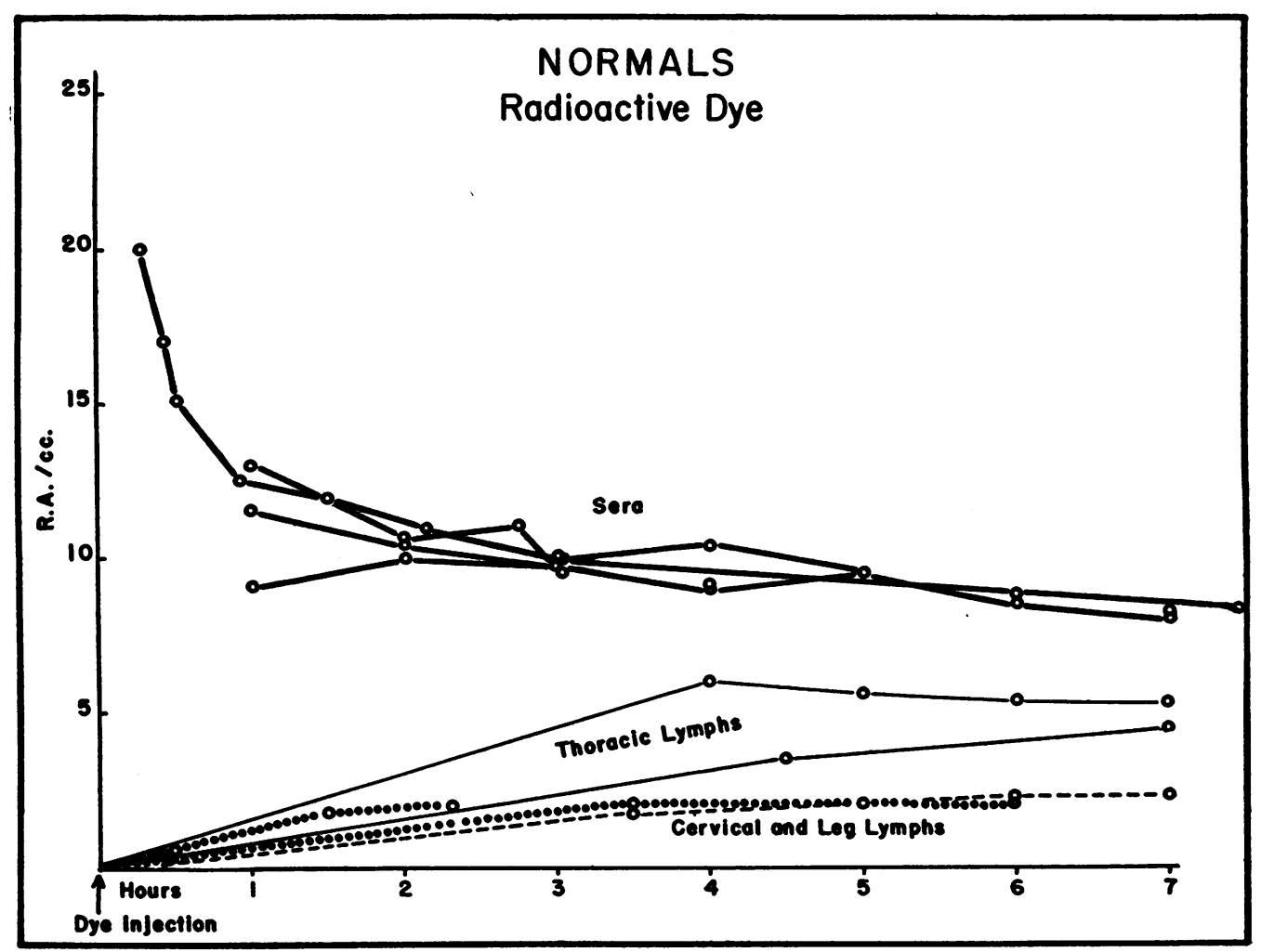

Fig. 2. The Concentration of Radioactivity in Blood Serum, Thoracic, Cervical, and Leg Lymph Following the Intravenous Injection of Radioactive Dye in 4 Normal Dogs, 1 Under Novocaine and 3 Under Nembutal ANEsthesia

The rate of equilibration following injection of dye is slower than after injection of the bromide ion. The concentration in lymphs does not become constant until after the second hour; equality with serum is not reached.

lymphatic vessel and of the exact relation of lymph to interstitial fluid. Drinker and his collaborators have developed the concept that the fluid in a lymphatic trunk is essentially interstitial fluid since no anatomic structure which might act as a semi-permeable membrane has been demonstrated at the entrance to the lymphatic vessels. It is possible, however, that water is reabsorbed into the blood stream at the venous end of the capillary from the interstitial fluid just as this fluid enters the collecting lymphatic. This would result in an increased concentration in the lymph, as compared to the interstitial fluid, of those substances, such as protein, which pass only slowly through the capillary membrane. The more rapidly a substance injected into the blood stream can be identified in the lymphatic, the closer the lymphatics are functionally to the capillary mem- brane, and the more comparable lymph should be to interstitial fluid.

In order to determine how rapidly an ion, readily permeable through the capillary membrane, comes into equilibrium in the body fluids, radioactive bromide ion, as the sodium salt, was injected intravenously. The concentrations of the radioactivity were followed in the blood stream and in the leg, cervical, and thoracic lymph at 5-minute intervals. The results are shown in Figure 1. A rapid fall in the concentration of radioactivity was found in the blood stream, and a rapid rise in all the lymphs. At 20 minutes, the radioactivity of the 4 fluids was equal, that is, equilibrium had been reached, and continued equilibrium was observed throughout the 3 hours of the experiment. This demonstrates graphically the permeability of normal capillaries to a small inorganic ion and is to be 


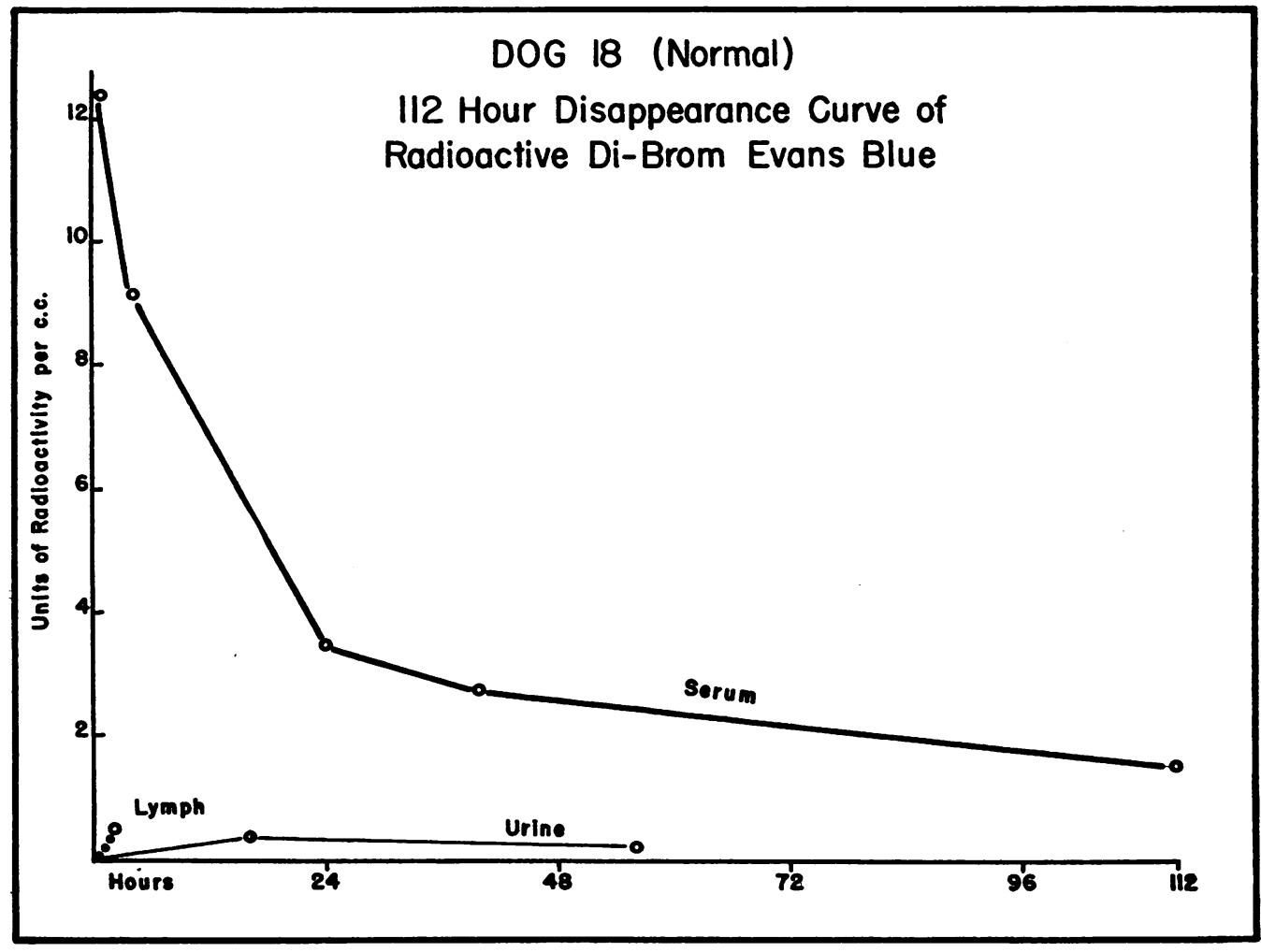

Fig. 3. One Hundred and Twelve Hour Disappearance Curve of Radioactive Evans Blue Dye in the Blood Seruy of a Noryal Dog

contrasted to their impermeability to the large organic colloidal molecules, demonstrated in the succeeding sections. In certain pathologic conditions, this distinction is virtually lost, and the capillary becomes almost as permeable to the colloids as it formerly was only to ions.

The appearance of significant amounts of radioactive bromide ion in the lymphs from the 3 areas in so short a period and the rapid achievement of equilibrium between blood and lymph demonstrates the physiologic proximity of fluid within the lymphatic trunk to interstitial fluid and the capillary membrane. It is to be emphasized that in this experiment, nembutal anesthesia was used, and there was no trauma except that incident to the cannulation of the lymphatics. No burn was performed.

\section{Normal distribution of radioactive proteins}

In order to learn the normal distribution of the dye-protein molecule between blood and lymph from various areas, radioactive dye was injected into 13 dogs which were not burned. In 10 , the lymphatic cannulations and sample collections were made under local anesthesia (1 per cent procaine). The other 3 were maintained under nembutal. No difference in dyeprotein distribution was noted between the 2 groups. ${ }^{6}$ The results in 4 of the experiments are shown in Figure 2.

The important finding in these normal animals is that the lymph and blood curves form a characteristic pattern, rendering the normal state of capillary permeability readily definable by this technic. Although there are minor variations between animals, there are limits of normal to the concentration of the radioactive dye in the lymph. The serum disappearance curve is a slope which falls at a constantly decreasing rate. ${ }^{7}$

\footnotetext{
- Since these experiments were concluded, Beecher and his collaborators (15) have shown that nembutal decreases the flow of lymph. Our experiments are consistent with this finding.

The disappearance of radioactivity in the serum in the
} 


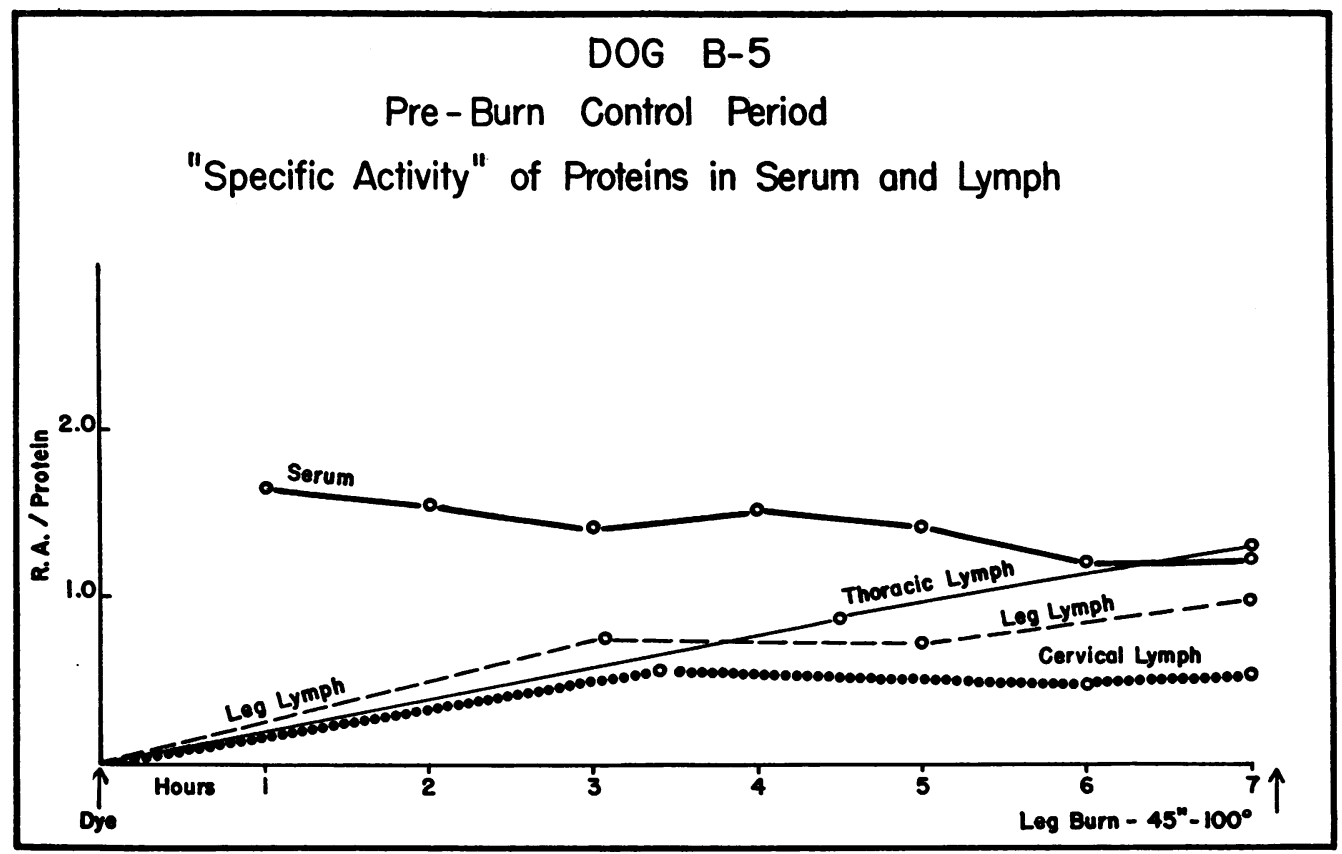

Fig. 4. "Specific Activity" of Proteins in Serum and Lymph Following Intravenous Injection of Radioactive Dye in an Unburned Dog Under Nembutal

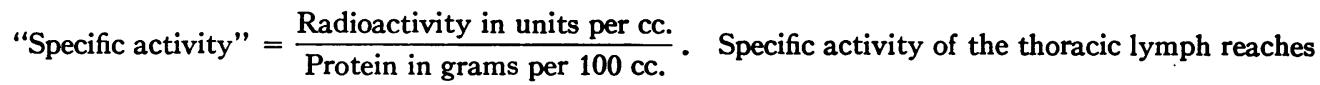
that of the serum between the sixth and seventh hour, indicating that thoracic lymph is in equilibrium with serum at that time. At the seventh hour, the specific activity of neither leg nor cervical lymph has reached that of the serum.

The concentration of radioactivity in peripheral lymph (cervical and leg) tends to fall in the range of 1.0 to 2.0 units per cc. Any value above 2.5 units per cc. (a 25 per cent increase over normal) is regarded as pathologic. The concentration in thoracic lymph rarely reaches a 3-hour plateau higher than 5 units per cc. in the normal animal.

The disappearance curve of the dye in the blood serum was followed in 1 normal animal for 112 hours (Figure 3 ). The colloidal dye is very slow to leave the blood stream completely and, in fact, at $\mathbf{1 1 2}$ hours is still at about one-sixth of its 1-hour value. The slope is one of decrease at a constantly decreasing rate. ${ }^{8}$

first hour was measured in only 1 animal of this group as we have not found its steep slope significant for our purposes; after the 1-hour reading, the values tend to coincide.

8 The radioactivity recovered in the urine and lymph in the first 56 hours of this experiment accounted for but a small portion of that disappearing from the blood stream.
Since the dye is associated with protein in the plasma, it is of interest to determine the ratio of radioactive dye to total protein in serum and lymph. This will indicate to what extent equilibrium has been approached in the exchange of dye and protein across the capillary. If the ratios in serum and lymph are equal, then no matter what the absolute values of the various components are, equilibrium has been reached.

Assuming that the dye is "bound" to protein, this ratio of dye to protein may be termed the specific activity of the protein, that is, the amount of radioactivity per unit protein, and in general terms:

Specific activity of the protein

$$
=\frac{\text { Radioactivity per unit volume }}{\text { Protein per unit volume }}
$$

Using such an expression, if the specific activi-

Other evidence (13) has shown that a large part of the dye is slowly excreted in the bile and feces. 


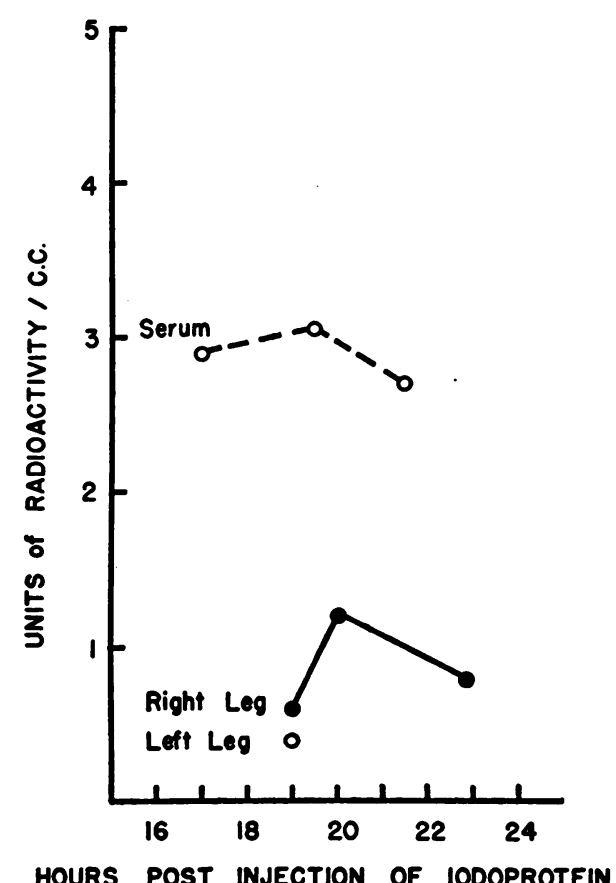

Fig. 5. Radioactivity in Blood Serum and Lymph from Both Hind Legs of an UNBURNed Dog Under Nembutal, 17 to 23 Hours After the Intravenous InJection of Radioactive IODOPROTEIN

(a) Concentrations of radioactivity. Serum and lymph have not reached equality.

(b) Specific activity (radioactivity per unit of protein). This calculation suggests that the peripheral lymph has reached, by this time, equilibrium with the serum.

ties on the two sides of the capillary are the same, equilibration has taken place and exchange of dye-protein has reached a point beyond which it cannot theoretically progress so long as the dye molecules stay attached to protein molecules, and so long as we are dealing with a passive membrane which does not exert any force to exclude dye from one side or the other.

The validity of these theoretical considerations is borne out by the fact that when specific activities are computed for serum and lymph, we do indeed find that, in certain pathologic conditions, exchange reaches equilibrium, whereas in the control animal, where permeability to these colloids should be limited, such equilibrium is not reached save in the case of thoracic lymph. As is well known (16), the protein concentration of thoracic lymph is considerably higher than that of peripheral lymph, and in its content of albumin approaches that of plasma. ${ }^{9}$

The results of the calculation of specific activity in terms of the total protein are shown in Figure 4, which is to be contrasted with Figure 2. In Figure 2, the concentration of radioactive units per cc. is shown. In Figure 4, the specific activity of the proteins present has been computed according to the formula:

Specific activity $=\frac{\text { Radioactivity in units per cc. }}{\text { Protein in grams per } 100 \mathrm{cc} \text {. }}$

- Calculation of the specific activity of the protein is complicated by two factors: one, that the dye is preferentially bound to albumin (12), and the other that the albumin-globulin ratio in lymph may be raised following a burn, as mentioned later. We have not measured these variables quantitatively and have found the calculation presented above satisfactory for our present purposes. 


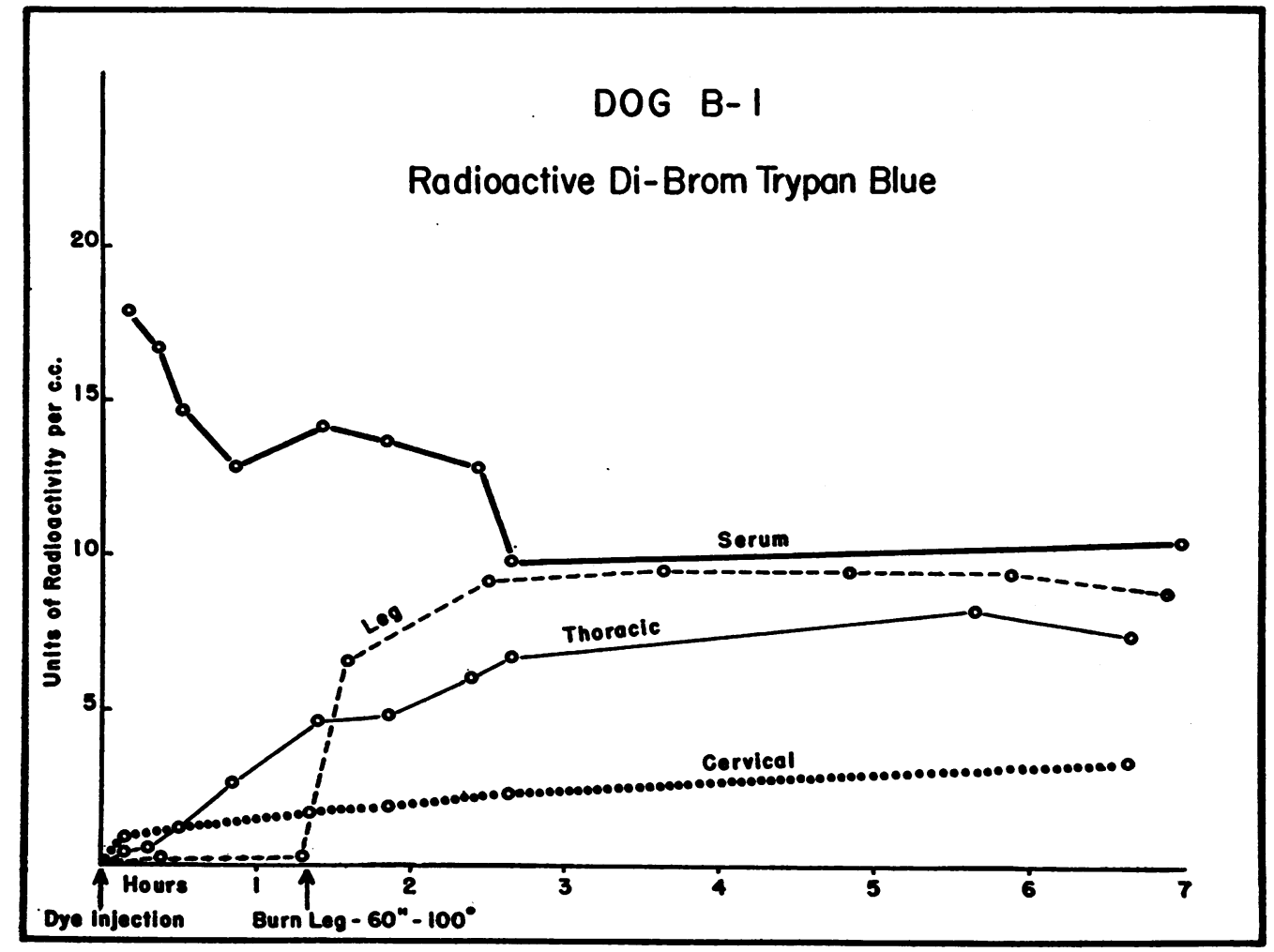

\section{DOG B-I}

"Specific Activity" of Proteins in Serum and Lymph

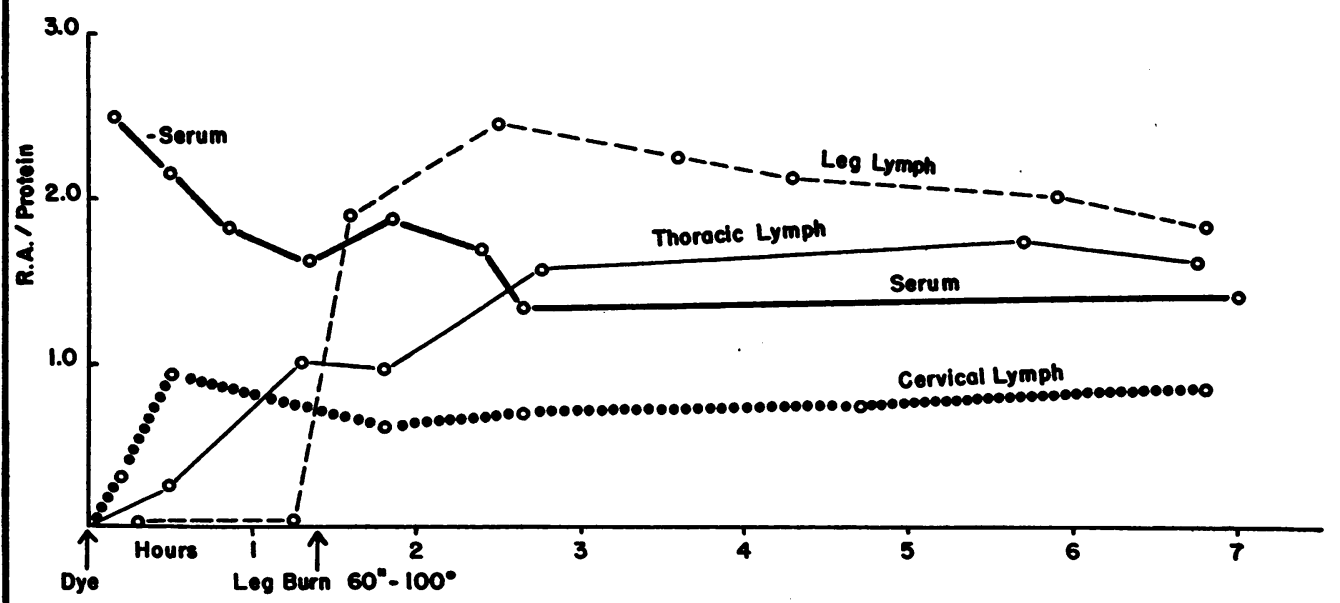

Fig. 6. The Effect on the Distribution of Radionctive Dye Between Blood and Lymph of a Hot Water Burn of the Leg of a Dog Under Nembutal

The burn was severe, boiling water for 60 seconds.

(a) Concentration of radioactivity. Immediately following the burn, there is an abrupt rise in concentration in the lymph from the burned leg which reaches that of the blood serum within 2 hours. In the blood serum, 


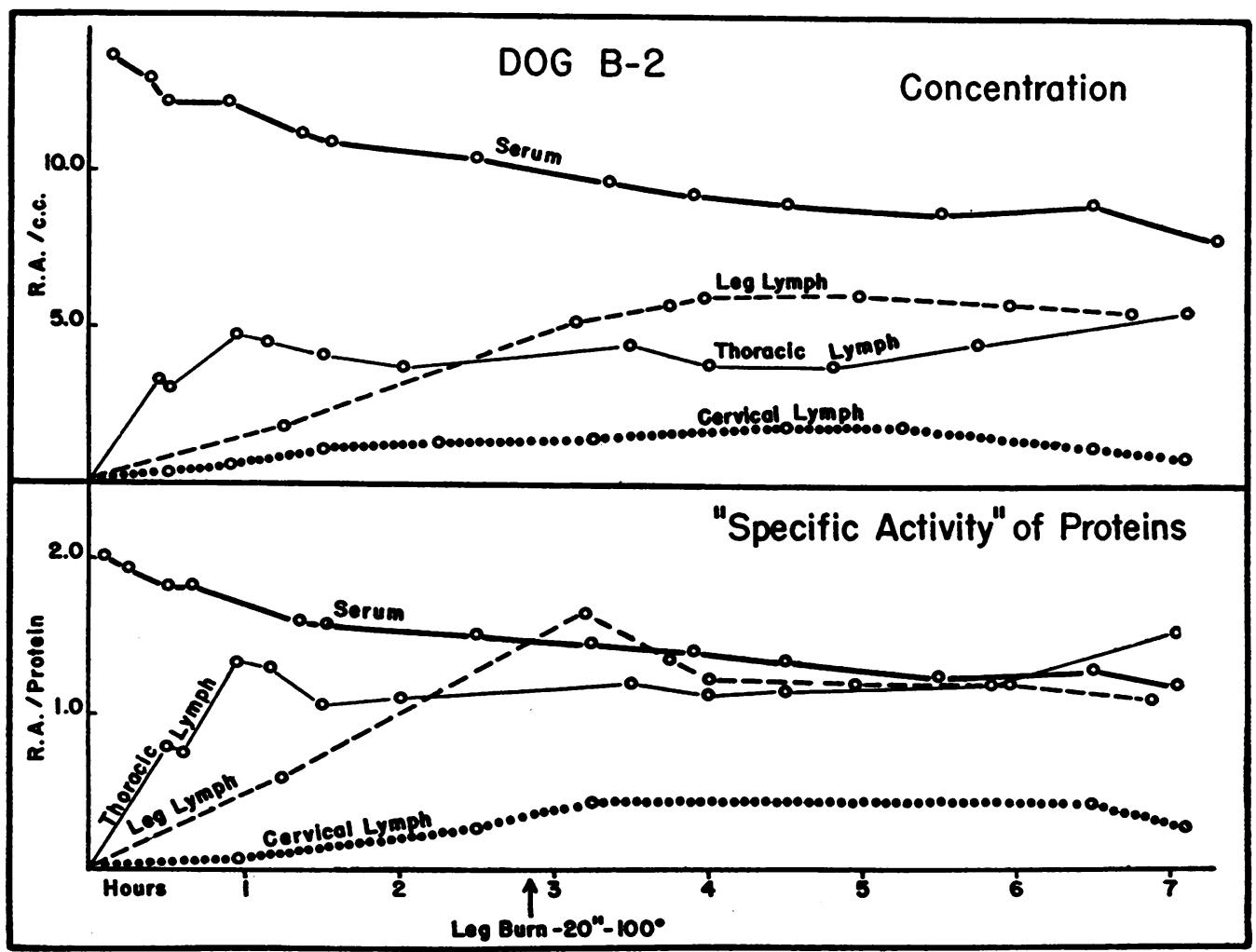

Fig. 7. Concentrations of Radioactive Di-Brom Evans Blue and Specific Activity of Protein in Blood Seruy and Lymph in a Dog Under Nembutal Before and After the Burn of a Hind Leg with Hot Water

The burn was less severe than that in the experiment of Figure 6, boiling water for 20 seconds. The concentration of radioactivity in the lymph from the burned area did not reach that of the blood serum; the specific activity was equal to but not greater than that of the serum after the burn for the 4 hours before sacrifice of the $\operatorname{dog}$.

It will be noted that in the normal animal, thoracic lymph reaches equilibrium with serum (the curves come together) in about 6 hours, whereas the peripheral lymph does not reach equilibrium at this time. This is in contrast to the pathologic conditions described below.

In Figure $5 \mathrm{a}$ and $\mathrm{b}$, are shown the radioactivity and specific activity in serum and leg lymph of a radioactive iodoprotein, 17 to 23 hours after its injection into the blood stream.
After this long interval, equilibration has been reached between the 2 fluids. The radioactive iodoprotein ${ }^{10}$ used in this experiment has the advantage of a longer half life, 8 days as compared with 34 hours for radioactive bromine.

${ }^{10}$ The iodoprotein and the bromoprotein, used in the experiment shown in Figure 11, were kindly prepared for us by Dr. Arnold M. Seligman. Radioactive iodine and bromine were conjugated with dog serum proteins in vitro, as described by Fine and Seligman (5).

immediately following the burn, there is a slight rise in concentration of radioactivity; such an interruption in the smooth slope of the serum curve immediately following the burn has been encountered in several experiments. The thoracic or cervical lymphs for the 7 hours before the animal was sacrificed showed no departure from normal.

(b) Specific activity. This radioactivity-protein ratio was higher in the lymph from the burned leg than in the blood serum. This calculation suggests that the radioactive dye is bound preferentially to a portion of the serum protein which escapes in the burned area in greater proportion. The activity of thoracic lymph reaches that of the blood stream at $21 / 2$ hours while the cervical lymph from a non-burned area does not reach equilibrium in the 7 hours of the experiment. 

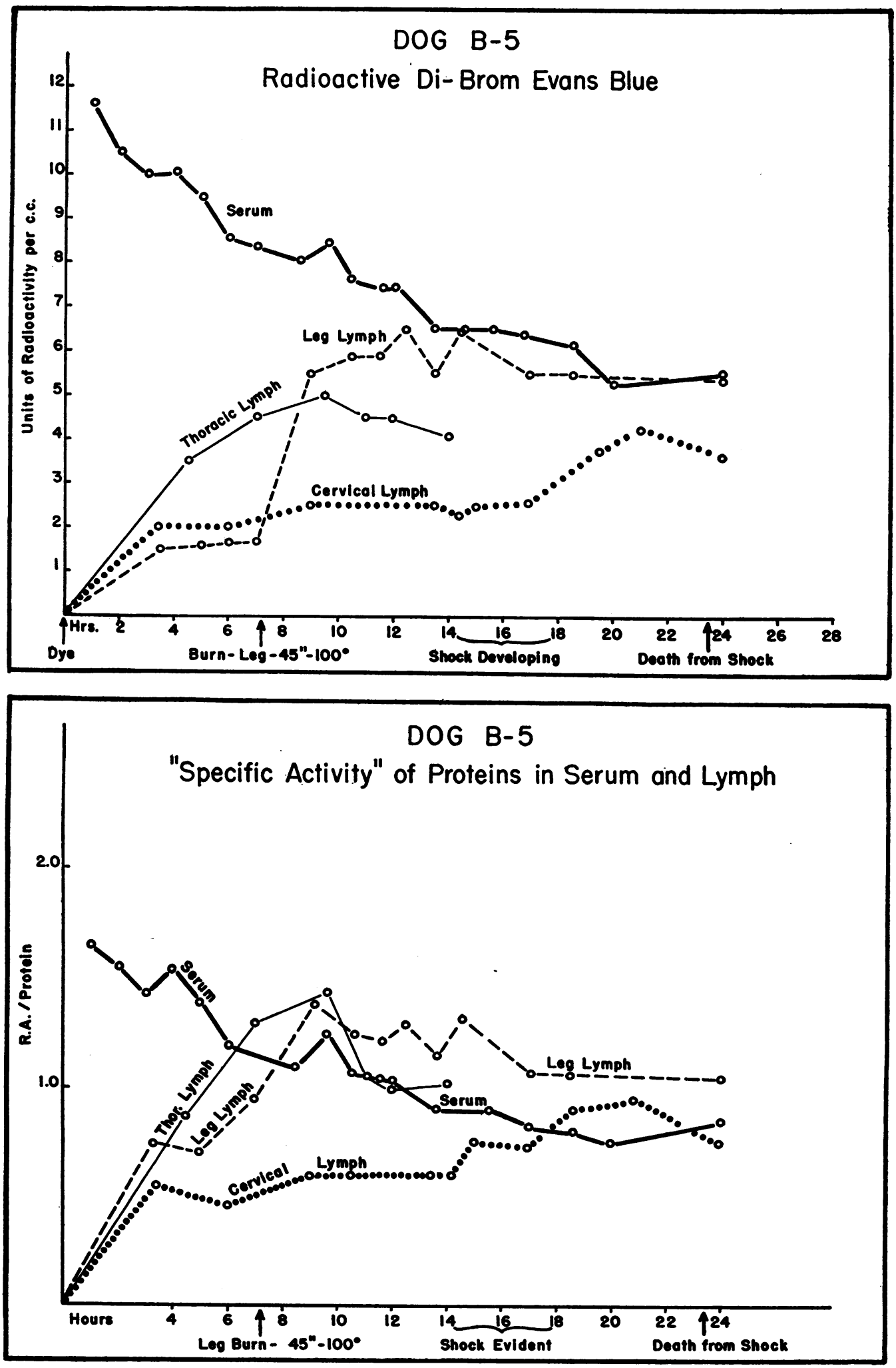

FIG. 8. 


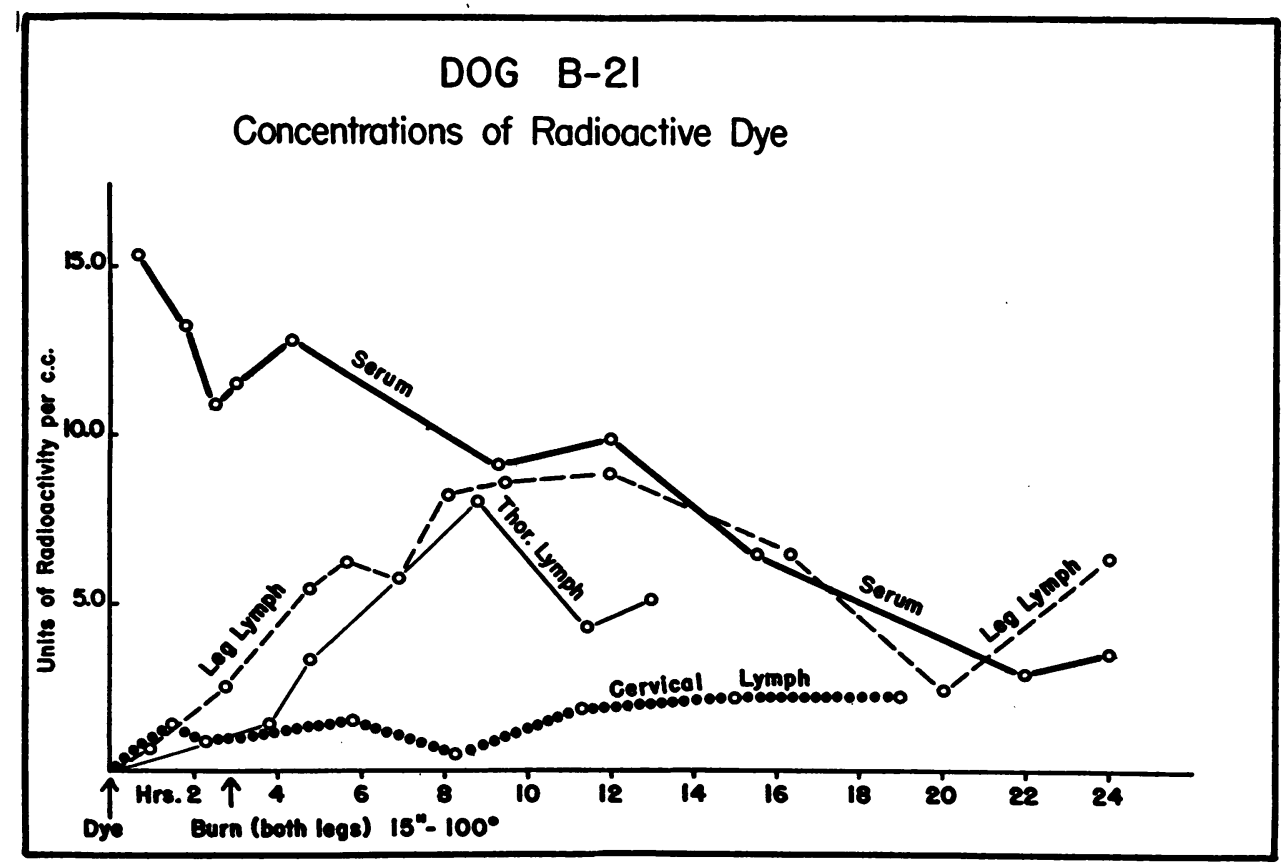

Fig. 9. Concentrations of Radioactive Dye in Blood Serum and Lymphs in a Dog Under Nembutal Followed Until Death in Burn Shock

Both hind legs were burned in boiling water for 15 seconds. The concentration of radioactivity in the lymph from the burned area reached that of the blood stream more slowly than in the experiment with a more severe burn (Figure 6). The flow of lymph from the non-burned area, drained by the cervical trunk, ceased after the animal had been in shock for a few hours; while lymph was still flowing, no change occurred to suggest a change in capillary permeability.

That radioactive halogenated proteins are treated similarly to the dye proteins by the capillary membrane is suggested by the observation with bromoprotein, shown in Figure 11, and described in the succeeding section.

\section{Effect of burns on capillary permeability}

As anticipated from the work of Drinker and his collaborators $(6,7)$, the flow and protein concentration of lymph is increased from the burned leg of a dog. After immersion of the foot and ankle in boiling water, the flow from the lymphatic trunk just above the burned area rises many-fold, and the protein concentration rises from 2 to 2.5 grams, to 4.5 to 5.0 grams per 100 cc. ${ }^{11}$ The flow rapidly reaches a maximum, usually within the first half hour, and slowly falls off during the next 5 hours, as edema of the burned area increases. When maximum edema of the burned area has been reached, the flow has descended to a low plateau, above the pre-burn flow, at which rate it remains until either the blood pressure falls to a low level or the swelling rises above the burn to the cannula, shutting off the lymphatic trunk. The rise in protein concentration is sustained.

1 The effect of temperature and duration of the burn on lymph flow and protein concentration will be detailed in a subsequent paper from this laboratory (17).

Fig. 8. The Radionctivity of the Blood Serum and Lymphs of a Dog Under nembutal Observed Until Death in Burn Shock

Both hind legs were severely burned, boiling water for $\mathbf{4 5}$ seconds. Changes occurred in lymph from the burned area similar to those shown in Figure 6. Following the development of low blood pressure shock, there was evidence of increased permeability in the non-burned areas of the head drained by the cervical lymphatic trunk.

(a) Concentration of radioactivity.

(b) Specific activity. 
When radioactive dye has been injected into the dog previous to immersion of the foot in hot water, there is a prompt rise in radioactivity immediately following the burn as might be expected from the rise in protein concentration. If the burn has been severe (boiling water for 15 seconds or longer), the concentration of radioactivity of the lymph from the burned area rapidly reaches that of the blood serum. When this happens, the specific activity of the lymph will be above that of the serum, since the total serum protein averages 2 grams more than the lymph protein, even after burning. In Figure 6 $a$ and $b$, are depicted the findings in a dog of which a leg was immersed in boiling water for 60 seconds. There is no deviation from the normal in the radioactivity concentration in the lymph from the cervical and thoracic unburned areas for the 6 hours before the dog was sacrificed. Two similar short experiments produced comparable but not identical results; the data of one are shown in Figure 7, in which the burn was not as severe and the effect upon the capillary premeability less (see legend).

The only possible explanation for the equality of radioactivity in lymph and serum and for the greater specific activity of lymph following a severe burn is that the radioactive dye is preferentially attached to one portion of the serum protein and that this portion exudes through the damaged capillaries in greater proportion. This is indirect, confirmatory evidence of the finding of Rawson (12), that the Evans and trypan blue dyes bind themselves to the albumin of the serum. ${ }^{12}$

In 5 experiments, the blood and lymph of dogs with burned legs were observed until death in shock from 17 to 27 hours after burning. These

12 In other dogs similarly burned, the albumin-globulin ratio, determined by precipitation methods, of the postburn lymph is, in general, increased and is greater than that of the serum.

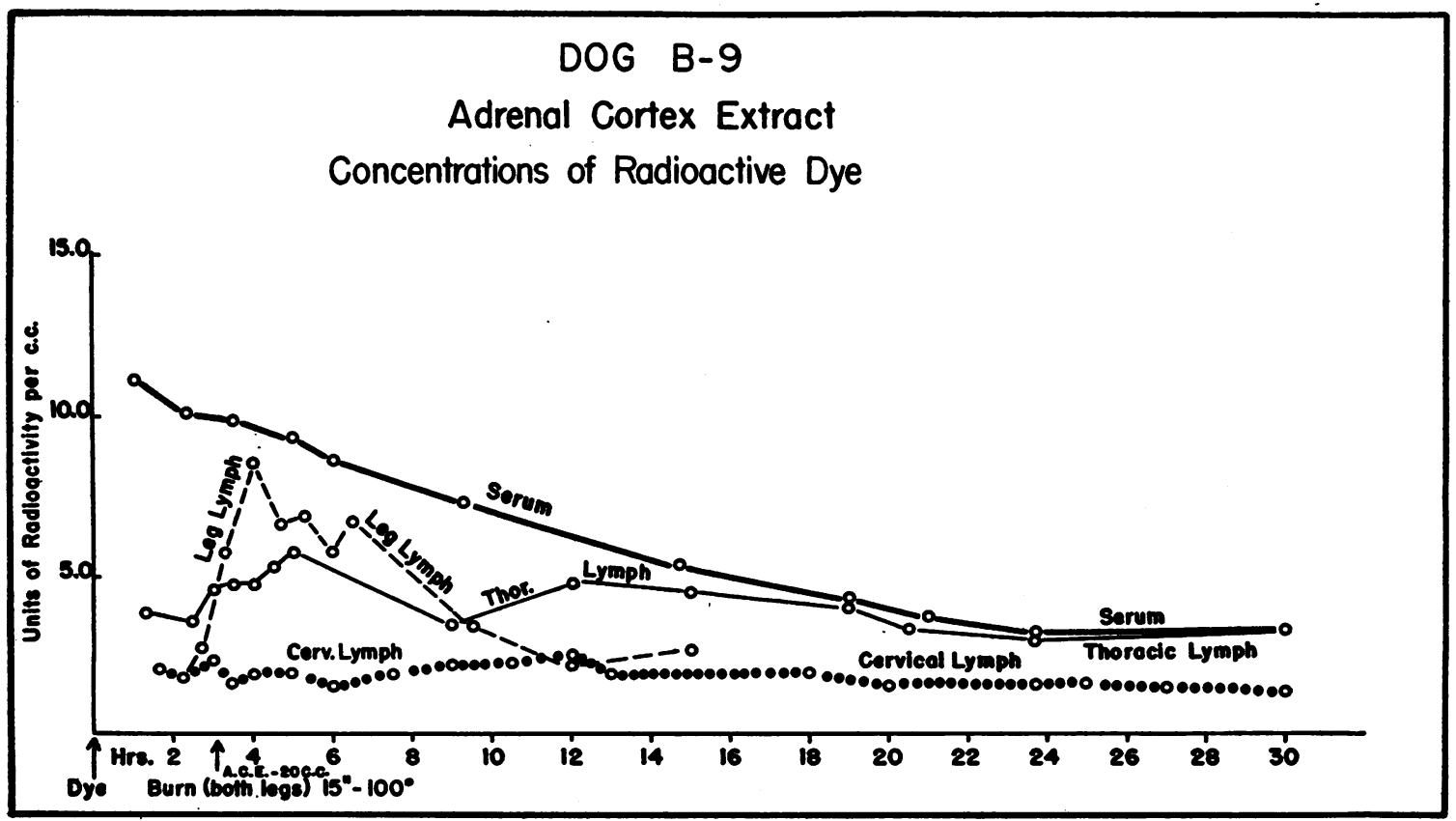

Fig. 10. Concentration of Radioactive Dye in Blood Serum and Lymphs in a Dog Burned, Given Adrenal Cortical Extract Intravenously, and Followed Until Death in Shock

Extract, $20 \mathrm{cc}$., was given immediately following a burn of both hind legs in boiling water for 15 seconds. The concentration of radioactivity of the lymph from the burned area rose precipitously but remained at a level below that of the serum for the 12 hours during which the flow continued. This observation is not considered significantly different from those in other experiments where no extract was injected. No deviation in the course of the concentration of the radioactivity in the serum, thoracic, and cervical lymph from the other experiments was noted. There was no evidence of increased capillary permeability in the non-burned region at any time before death. 
experiments of long duration were planned to obtain evidence regarding possible changes in capillary permeability in areas of the body remote from the burn, in contrast to the experiments of short duration, in the first part of this section, in which local changes only were found. In 4 of the 5 dogs, both hind legs were immersed in hot water to increase the area burned and hasten the onset of shock. All of the animals died following a period of low blood pressure with hemoconcentration and other findings in the blood typical of shock from burns. In only one, the first experiment, was evidence found in an area remote from the burn of increased capillary permeability which could be ascribed to shock. The data of this experiment are shown in Figure
$8 \mathrm{a}$ and $\mathrm{b}$. From the fourteenth to the eighteenth hours, the mean arterial pressure gradually fell to a level below $80 \mathrm{~mm}$. Hg. From the twentieth to the twenty-fourth hours, the lymph from the cervical trunk showed an increased concentration of radioactivity, consistent with an increase in permeability. This increase is approximately 25 per cent above normal, an order of magnitude considered significant by this technic. There was no evidence of infection in either the upper respiratory passages or the cannulation wound which could account for the increase in permeability (see section 5). The findings in the lymph from the burned area were identical with those of the short experiments. The thoracic duct

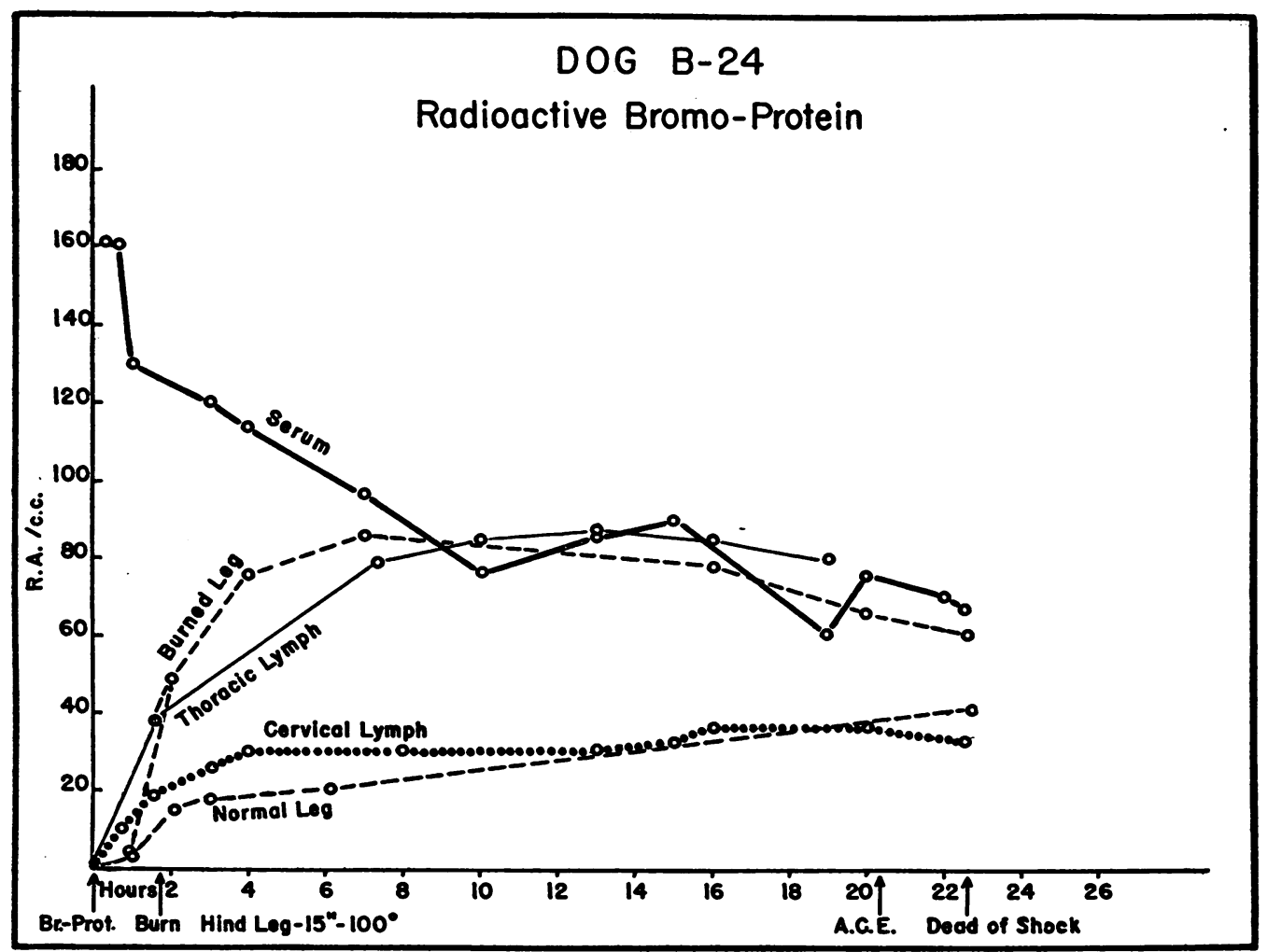

Fig. 11. Concentration of Radioactivity in Blood Serum and Lymphs Following the Injection of Radioactive Bromoprotein in a Dog UNDER Nembutal, BuRNed, and Given Adrenal Cortical Extract in the Late Stage of Shock

One hind leg was burned in boiling water for 15 seconds; the expected rise in radioactivity occurred in the lymph from this area. There was no deviation in radioactivity in the lymph from the non-burned leg or head from that expected in a control dog. There was, therefore, no indication of any change in capillary permeability in the non-burned areas. Two hours before death, when the dog was in severe shock, $30 \mathrm{cc}$. of adrenal cortical extract was injected intravenously without any apparent effect. 
cannula became plugged before the development of shock.

In Figure 9 are shown the data of the second experiment in which no change in permeability was demonstrated in the cervical lymph from a non-burned area. The animal developed shock associated with low blood pressure and hemoconcentration. Flow in the cervical lymphatic trunk ceased 4 hours before death, presumably because of continued diminished blood flow; the last sample of cervical lymph was collected when the animal was already in profound shock. The expected changes in concentration and flow were demonstrated in the lymph from the burned leg.

The other 3 experiments of long duration are described in the next 2 sections.

\section{Effect of adrenal cortical extract on capillary permeability induced by burns}

Adrenal cortical extract has been recommended as a therapy in burn shock $(18,19)$. It is probable that the adrenal cortex exerts an influence on capillary permeability in adrenal cortical insufficiency (20). In 3 of the long duration experiments, adrenal cortical extract was administered. ${ }^{13}$ In 2 , the extract was given immediately following the burn (Figures 10 and 12), and in 1, late in shock, 19 hours after the burn and 2 hours before death (Figure 11). The extract neither prevented nor reversed the changes in capillary

${ }^{13}$ We are indebted to The Upjohn Company for generous supplies of a potent extract of the adrenal cortex.

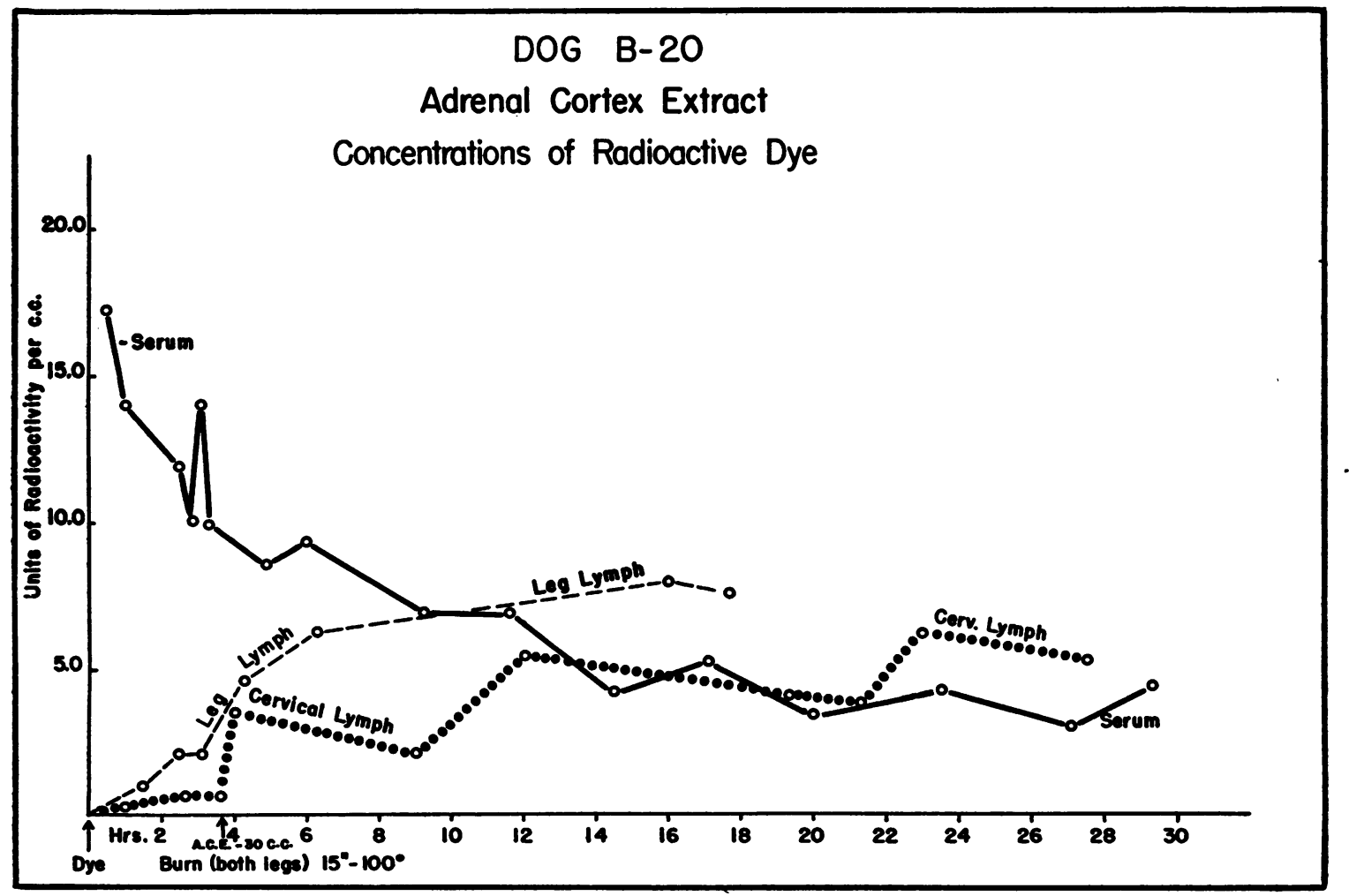

Fig. 12. Concentrations of Radioactivity in Blood Serum and Lymphs in an Animal Burned, Given Adrenal Cortical Extract, and Dying with Evidence of Infection in Head and Neck

Both hind legs were burned in boiling water for 15 seconds. Adrenal cortical extract, 30 cc., was injected immediately following the burn. The concentration of radioactivity in the lymph from the burned area rose abruptly and eventually more than equalled that of the blood serum in a manner comparable to the experiments in which no extract was given. A rise in concentration was observed in the cervical lymph 4 hours after the onset of the experiment which continued slowly until 7 hours before death when the concentration was higher than that of the blood serum. Post mortem examination showed a purulent infection of nasopharynx, mouth, trachea, and cervical cannulation wound. It is considered that the infection accounts for the alterations in capillary permeability, indicated by the increased concentration of radioactivity in the cervical lymph. 
permeability in the burned area, and it did not influence the permeability in the non-burned regions.

\section{Infection and capillary permeability}

The experiment in Figure 12 illustrates a change in permeability which is the result of a complicating infectious process rather than of the burn. It is probable that the dog had an antecedent infection of the upper respiratory passages. The experiment warns against the unwitting use of an infected animal and emphasizes the necessity of maintaining strict aseptic precautions throughout the surgical procedures of lymphatic cannulation in such experiments.

An alteration in permeability is demonstrated in that portion of the head drained by the cervical lymphatic trunk in addition to that encountered in the burned leg. This change in the nonburned area was unexpected because it occurred soon after the burn and onset of the experiment, and long before the animal showed manifestations of shock. The altered permeability was maintained throughout the remaining 24 hours of the experiment, and at the thirteenth hour, the radioactivity in the cervical lymph equalled that of the blood. At post mortem examination, the mouth, nasopharynx, and trachea were filled with greenish, purulent exudate, and the cervical cannula wound was grossly infected. There was undoubtedly an acute inflammatory process in the region from which the lymph was flowing into the cervical lymphatic trunk. It is believed that this process was responsible for the demonstrated change in capillary permeability.

\section{COMMENT}

The observations on the distribution of radioactive molecules between blood and lymph recorded in this paper add to the understanding of certain physiologic mechanisms of the normal circulation, as well as of the abnormal, induced by burns. A rapid exchange of electrolyte and a slower exchange of protein through the interstitial space is recorded. A considerable proportion of the plasma protein circulates outside of the blood stream.

The Evans (T-1824) and trypan blue dyes have been widely used to measure plasma volume and there has been disagreement regarding the correct interpretation of the falling concentration of dye in the blood stream after injection. The experiments in this paper show that the dyes measure not plasma volume but truly the fraction of the plasma protein with which they combine, whether this protein remains in the blood stream or escapes into the interstitial spaces. The observations do not invalidate the dye method of estimation of plasma volume but lead to a different interpretation of the slope of disappearance of dye from the blood stream.

The rate of disappearance of dye in the blood stream is not an accurate measure of change in capillary permeability. In the experiments in this paper, local changes in permeability have been demonstrated in portions of the body large enough to affect eventually the circulating blood volume, yet the slope of dye disappearance is not significantly altered from that of normal control animals.

The experiments described in this paper confirm the gross change in capillary permeability found after a hot water burn and the concept of Drinker that lymph flow and the concentration of protein in lymph are a measure of capillary permeability. The addition of a radioactive protein to the blood stream permits sensitive detection of changes in permeability and proves them not to be false changes due to altered blood flow.

The observations on generalized permeability late in burn shock can only be considered to be preliminary. The abnormal permeability which appeared in the non-burned area late in burn shock in one experiment is without explanation. It is possible that had the dogs been more extensively burned, the remote change in permeability would have been observed more consistently. This is suggested by the experiments reported from Philadelphia (21) in which an increase in permeability in a non-burned area in a dog following an extensive burn was demonstrated by immunologic identification of foreign protein in the lymph.

The measurement of capillary permeability based upon the relation of colloid concentration in lymph and blood serum is open to erroneous interpretation when infection due to contamination in the experimental wound is present. Infectious inflammation is accompanied by altered 
permeability. With the decreased blood flow of shock in peripheral tissues and the consequent anoxia, anaerobic infections flourish, and changes due to the infectious process may appear in a few hours.

\section{SUMMARY}

A study of capillary permeability has been made in dogs by injecting radioactive colloids into the blood stream and measuring their appearance in the lymph from various areas. The colloids represent tagged molecules and their concentration in the lymph is a function of capillary permeability. Radioactive brominated di-azo dyes which form a bond with plasma proteins, and brominated and iodinated radioactive plasma proteins were used.

Radioactive bromide ion is found in the leg, cervical, and thoracic lymph within 5 minutes after intravenous injection; in 20 minutes, radioactive equilibrium has been reached between these lymphs and the blood serum. This observation indicates the rapidity with which an inorganic ion traverses the capillary membrane and the interstitial space. In contrast, the rise in concentration of radioactivity in the lymph following injection of the radioactive colloids is slow and equality is not reached under control conditions.

Following a hot water burn of a leg, the concentration of radioactive colloids in the lymph from this leg rises abruptly and approaches that encountered after injection of the inorganic ion. This indicates that in a pathologic state the capillary membrane may become as permeable to colloids as it formerly was only to ions.

The ratio of concentration of radioactivity to concentration of protein (specific activity) furnishes a measure of the extent to which equilibrium has been reached in the distribution of the tagged protein in the body fluids. Under control conditions, equal specific activities are eventually reached on either side of the capillary membrane. Following a burn, a specific activity, higher in the lymph than in the blood serum, may be observed, indicating a preferential escape through the capillary wall of one fraction of the plasma protein.

Evidence of increased capillary permeability in an area remote from the burn appeared in only one experiment late in shock.

Adrenal cortical extract injected intravenously exerted no detectable effect on either local or remote changes in capillary permeability.

The authors express their gratitude to Dr. Baldwin Curtis and the Cyclotron Staff of Harvard University, and to Professor Robley D. Evans and the Cyclotron Group of The Massachusetts Institute of Technology, for providing them with radiobromine.

\section{BIBLIOGRAPHY}

1. McCarrell, J. D., and Drinker, C. K., Cervical lymph production during histamine shock in the dog. Am. J. Physiol., 1941, 133, 64.

2. Krogh, A., The Anatomy and Physiology of Capillaries. Yale University Press, New Haven, 1929.

3. Landis, E. M., Capillary pressure and capillary permeability. Physiol. Rev., 1934, 14, 404.

4. Menkin, V., The Dynamics of Inflammation. Macmillan, New York, 1940.

5. Fine, J., and Seligman, A. M., Traumatic shock: IV. A study of the problem of the "lost plasma" in hemorrhagic shock by the use of radioactive plasma protein. J. Clin. Invest., 1943, 22, 285.

6. Field, M. E., Drinker, C. K., and White, J. C., Lymph pressures in sterile inflammation. J. Exper. Med., 1932, 56, 363.

7. Glenn, W. W. L., Petersen, D. K., and Drinker, C. K., The flow of lymph from burned tissue, with particular reference to the effects of fibrin formation upon lymph drainage and composition. Surgery, 1942, 12, 685.

8. Glenn, W. W. L., Muus, J., and Drinker, C. K., Observations on the physiology and biochemistry of quantitative burns. J. Clin. Invest., 1943, 22, 451.

9. Tobin, L. H., and Moore, F. D., Studies with radioactive di-azo dyes. II. The synthesis and properties of radioactive di-brom trypan blue and radioactive di-brom Evans blue. J. Clin. Invest., 1943, 22, 155.

10. Moore, F. D., and Tobin, L. H., Studies with radioactive di-azo dyes. I. The localization of radioactive di-brom trypan blue in inflammatory lesions. J. Clin. Invest., 1942, 21, 471.

11: Chapman, L. M., Greenberg, D. M., and Schmidt, C. L. A., Studies on the nature of the combination between certain acid dyes and proteins. J. Biol. Chem., 1927, 72, 707.

12. Rawson, R. A., The binding of T-1824 and structurally related diazo dyes by the plasma proteins. Am. J. Physiol., 1943, 138, 708.

13. Moore, F. D., Tobin, L. H., and Aub, J. C., Studies with radioactive di-azo dyes. III. The distribution of radicactive dyes in tumor-bearing mice. J. Clin. Invest., 1943, 22, 161. 
14. McCarrell, J. D., Lymphatic absorption from the nasopharynx. Am. J. Physiol., 1939, 126, 20.

15. Polderman, H., McCarrell, J. D., and Beecher, H. K., Effects of anaesthesia on lymph flow (local procaine, ether, pentobarbital sodium). J. Pharmacol. and Exper. Therap., 1943, 78, 400.

16. Drinker, C. K., and Yoffey, J. M., Lymphatics, Lymph, and Lymphoid Tissue. Harvard University Press, Cambridge, Mass., 1941.

17. Cope, O., Graham, J. R., and Mixter, G., Jr., To be published.

18. Rhoads, J. E., Wolff, W. A., and Lee, W. E., The use of adrenal cortical extract in the treatment of traumatic shock of burns. Ann. Surg., 1941, 113, 955.

19. Scudder, J., and Elliott, R. H. E., Jr., Controlled fluid therapy in burns. South. Med. and Surg., 1942, 104, 651.

20. Cope, O., Brenizer, A. G., Jr., and Polderman, H., Capillary permeability and the adrenal cortex. Studies of Eervical lymph in the adrenalectomized dog. Am. J. Physiol., 1942, 137, 69.

21. Netsky, M.G., and Leiter, S. S., Capillary permeability to horse proteins in burn-shock. Am. J. Physiol., 1943, 140, 1. 